Revista de

Contabilidade e Organizações

www.rco.usp.br
DOI: http://dx.doi.org/10.11606/issn.1982-6486.rco.2018.149212

Journal of

Accounting and

Organizations

\title{
Aprovação de contas municipais com irregularidades gravíssimas: quando a auditoria técnica não é suficiente
}

The approval of municipal accounts with very serious irregularities: when techincal audit is not suficient

Patricia Adriana Azambuja $a^{\text {; }}$ Aridelmo Teixeira ${ }^{a}$; Silvania Neris Nossa ${ }^{a}$

${ }^{a}$ Fucape Business School

Palavras-chave

Auditoria.

Contabilidade Pública.

Controle externo.

Influência política.

\begin{abstract}
Resumo
O estudo analisa a dinâmica dos votos de relatores e conselheiros no plenário do Tribunal de Contas de Mato Grosso. Eventuais irregularidades nas contas municipais de governos são apontadas no relatório de auditoria, que então segue para a análise do Ministério Público de contas para ser relatado e votado em plenário. Identificouse um processo de reversão dos apontamentos da auditoria, reduzindo a propensão à reprovação das contas mesmo na presença de irregularidades gravíssimas. $\mathrm{O}$ voto do relator tem uma grande influência no resultado da votação do pleno, e o fato do relator ser indicado politicamente implica na redução da probabilidade de reprovação das contas nestes casos.
\end{abstract}

Keywords

Audit.

Public Sector Accounting.

External control.

Political influence.
Informações do Artigo

Recebido: 21 de agosto de 2018

Aceito: 28 de dezembro de 2018

Publicado: 29 de dezembro de 2018

\begin{abstract}
The study analyzes the dynamics of the votes of rapporteurs and counselous at the collegiate decision of the Regional Court of Accounts of Mato Grosso. Eventual irregularities are identifyed by the audit report, which then is analyzed by the Public Prosecutor's Office and assigned to one of the counselors acting as rapporteur, and finally to be voted by the collegiate. It was identified a reversion in the auditors', appointments, reducing the propensity to reprove accounts with severe irregularities. The rapporteur vote has a great influence on the plenary outcome, and when the rapporteur is a political appointed conselour the probability to reprove irregular accounts is mitigated.
\end{abstract}

\section{Implicações práticas}

Os resultados podem interessar a especialistas em gestão pública, jornalistas, parlamentares que estudam os efeitos de influência política nos Tribunais de Contas no Brasil. A forma como estão organizados os Tribunais de Contas, com indicação política de conselheiros promove uma potencial proteção aos governos na análise das contas. Os resultados podem subsidiar a discussão da reestruturação dos Tribunais de Contas para assegurar o efetivo controle da administração pública no Brasil.

\section{INTRODUÇÃO}

A independência do auditor afeta a qualidade da auditoria (Tepalagul \& Lin, 2015), e aumenta a percepção do público sobre sua independência (Yu-Cheng et al., 2017). Sem o pressuposto da independência, a própria administração poderia apresentar as suas contas e avaliar seu próprio trabalho, de acordo com seus interesses (Houghton et al., 2005).

\footnotetext{
Autor Correspondente: Tel. (27) 4009-4438

E-mail: patricia_azambuja@hotmail.com (P. A. Azambuja. ); aridelmo@fucape.br (A. Teixeira); silvanianossa@fucape.br (S. N. Nossa)

Fucape Business School. Av. Fernando Ferrari, 1358 - Boa Vista - Vitória/ES - 29075010, Brasil..
} 
Alguns trabalhos alertam para a dificuldade e até a impossibilidade do pressuposto da independência da auditoria. Mesmo os auditores mais íntegros podem vir a fornecer julgamentos que respondam aos interesses das empresas que os contratam (Bazerman et al., 1997). O auditor independente assumiria uma responsabilidade que exige completa fidelidade à confiança pública, transcendendo qualquer relação de trabalho com o cliente (Bazerman et al., 1997). Contudo, no caso da auditoria de organizações públicas, a plena independência pode ser insustentável quando se busca averiguar atividades que são intrinsicamente políticas (Grasso e Sharkansky, 2001). Como será discutido, as apreciações das contas presentes nos relatórios elaborados pelos auditores de contas, ao serem apreciadas por conselheiros de indicação política, tem sua independência significativamente ameaçada.

Os Tribunais de Contas no Brasil são do modelo Napoleônico, formados por uma camada técnica (composta por auditores) e uma judicante (formada por ministros ou conselheiros). O que se discute é o grau de independência dos conselheiros ou ministros que atuam na camada judicante do Tribunal. Casos envolvendo irregularidades e má conduta de conselheiros e ministros estão sendo cada vez mais comuns na imprensa nacional.

No Tribunal de Contas da União, dos nove ministros titulares, quatro deles são investigados ou foram citados em inquéritos que apuram a prática de corrupção. Entre eles, atual presidente da corte, que está sendo formalmente investigado na operação da Lava Jato (O Dia; 02/04/2017). Já no Tribunal de Contas do Rio de Janeiro, seu presidente e mais quatro conselheiros foram presos e acusados de recebimentos de valores provenientes de desvio de recursos públicos (Albernaz, Silveira, \& Barreira, 2017). No estado de Mato Grosso, o Supremo Tribunal Federal (STF) determinou o afastamento de cinco conselheiros por denúncia de serem beneficiados em um esquema de corrupção (Araujo, 2017). O Supremo Tribunal Federal já tem o entendimento de que o cargo de controlador interno deve ser provido por concurso público (ADI 3062 GO). O próprio Tribunal de Contas do Estado do Mato Grosso entende essa obrigatoriedade para o cargo de controlador interno de ter uma condição independente (Parecer TCE/MT 041/2012). Contudo, apesar desse entendimento dos próprios órgãos de controle, o entendimento não se aplica para seus ministros e conselheiros.

Estudos empíricos no Brasil discutem os determinantes que influenciam a apreciação das contas municipais pelos diferentes Tribunais de Contas. Entre os determinantes tratados estão, a relação entre os gastos correntes, receitas municipais e dívidas consolidadas, em municípios de Santa Catarina (Lopes et al., 2008), volume de recursos, PIB e grau de escolaridade em municípios do Rio Grande do Sul (Ott et al., 2011), quantidade de profissionais da área contábil e resultado orçamentário em municípios do Espírito Santo (Velten , 2015). Ainda no Espírito Santo, a utilização de créditos adicionais suplementares pode diminuir a probabilidade de rejeição de contas, mas levar à aprovação das contas com ressalvas (Milanezi e Monte-mor, 2017). Os autores também destacam que o fato de o prefeito ter minoria na câmara municipal e a sua idade aumentam a probabilidade de rejeição das contas.

Os estudos de Velten (2015) e Milanezi e Monte-mor (2017) consideraram as informações provenientes do parecer definitivo do Tribunal de Contas e sua relação com variáveis de contexto externo. No entanto, não analisaram o relatório emitido pelos auditores daqueles Tribunais, que dão origem ao processo de apuração das contas, e seria o principal referencial para subsidiar os conselheiros no julgamento das contas (Manual de Auditoria Governamental do Tribunal de Contas de Mato Grosso, 2013).

No nosso melhor conhecimento, não identificamos estudos empíricos que tratem da reversão do resultado apontado pelos auditores nos seus relatórios, o voto do relator e sua validação no plenário do Tribunal. Ainda, sobre a aprovação de contas públicas em função da indicação política de conselheiros-relatores.

Nesta pesquisa identificamos a probabilidade dos relatores votarem favorável a aprovação de contas municipais com apontamentos de irregularidades gravíssimas, feitos pela equipe de auditoria. Os conselheiros tenderiam a seguir o voto do relatore dar o voto favorável à aprovação das contas. Testamos essa proposição para a análise das contas de 141 municípios do estado de Mato Grosso referentes aos exercícios de 2011 a 2015. A pesquisa assume que o relator verifica as irregularidades apontadas pela equipe técnica de auditoria, o parecer do Ministério Público de Contas (MPC), submete seu relatório com seu voto a apreciação a corte de contas abrangendo assim as principais etapas do processo de apreciação das contas municipais pelo Tribunal de Contas.

Os resultados demonstram que o plenário da corte de contas analisadas segue o voto do relator na maioria das apreciações, e que o voto do relator diverge do parecer do Ministério Público de Contas em grande parte dos casos. Esse pode ser um indício de que o relator não leva em consideração as irregularidades gravíssimas apontadas pela equipe técnica de auditores. O que suscita que a interferência política na nomeação dos conselheiros comprometeria a apreciação das contas municipais, e portanto a efetividade do Tribunal de Contas. Se confirmado, os Tribunais para terem sua independência recuperada teriam de ter a composição do plenário livre das indicações políticas, mudando a forma de ingresso a este cargo. Ainda, uma revisão da normatização quanto aos critérios a serem seguidos para apreciação das contas. 


\section{A DIFICULDADE OU IMPOSSIBILIDADE DO PRESSUPOSTO DA INDEPENDÊNCIA}

Os auditores além de serem qualificados devem exercer suas atividades de forma independente, pois o valor da auditoria depende fortemente da percepção do público sobre essa independência e, consequentemente, da confiança depositada nos auditores (Yu-Cheng et al., 2017). Uma auditoria "de valor" partiria de julgamentos e pontos de vista independentes da gestão e da diretoria da empresa auditada (no caso de empresas privadas), caso contrário são nada mais do que as vistas da própria gestão (Houghton et al., 2005). Assim, a qualidade da auditoria decorre de quanto o auditor consegue detectar e denunciar uma irregularidade, portanto, sem o pressuposto da independência é menos provável que o auditor venha a relatar irregularidades (DeAngelo, 1981).

Em organizações de auditoria de governos, como guardiões independentes do interesse público (Dye \& Stapenhurst, 1998) a transparência fiscal e a credibilidade nos demonstrativos financeiros públicos também dependem de independência de auditores para certificar regularidade da gestão dos recursos públicos (Suzart, 2012). Contudo, tal independência não é facilmente alcançada (Bazerman et al., 1997). Memso os auditores mais íntegros podem vir a fornecer julgamentos que respondam aos interesses dos que os contratam e remuneram, no contexto do setor privado (Bazerman et al., 1997).

Porém, a visão da plena independência da auditoria é insustentável quando se busca averiguar atividades que são intrinsicamente políticas (Grasso \& Sharkansky, 2001). No caso dos Tribunais de Contas, a questão da independência se desdobra nas duas camadas - técnica de auditores e judicante de natureza política (Loureiro, Teixeira, \& Moraes, 2009). Tanto auditores, em geral servidores públicos concursados, devem ser independentes, quanto conselheiros, apontados politicamente ou de carreira técnica - devem ter mesma independência em relação aos governos de seus jurisdicionados. O Tribunal de Contas é significativamente suscetível à interferência política, uma vez que os conselheiros são designados pelo executivo e legislativo (Gomes, 2006). Se o relatório de auditoria passa pelo crivo de conselheiros, escolhidos por meio de indicação política, a independência fique comprometida nos Tribunais de Contas.

\section{OS TRIBUNAIS DE CONTAS E A APRECIAÇÃO DAS CONTAS}

No âmbito governamental brasileiro, o controle externo é exercido pelo poder legislativo com o auxílio do Tribunal de Contas, responsável pela fiscalização quanto à legalidade, economicidade, moralidade e demais princípios que norteiam a Administração Pública brasileira (Ott et al., 2011). Assim, o controle externo sobre as contas dos municípios é exercido pelas Câmaras Municipais com o apoio dos Tribunais de Contas, que expressam, por meio de pareceres, seus posicionamentos com base em informações evidenciadas pela contabilidade (Lopes et al., 2008).

Qualquer pessoa ou entidade responsável por arrecadar e administrar qualquer espécie de bem público é submetida ao controle externo do Tribunal de Contas. Tal controle consiste em uma fiscalização exercida por meio de auditoria contábil, financeira, orçamentária, operacional e patrimonial (Gomes, 2006). A Figura 1 representa o ciclo de apreciação das Contas Municipais.
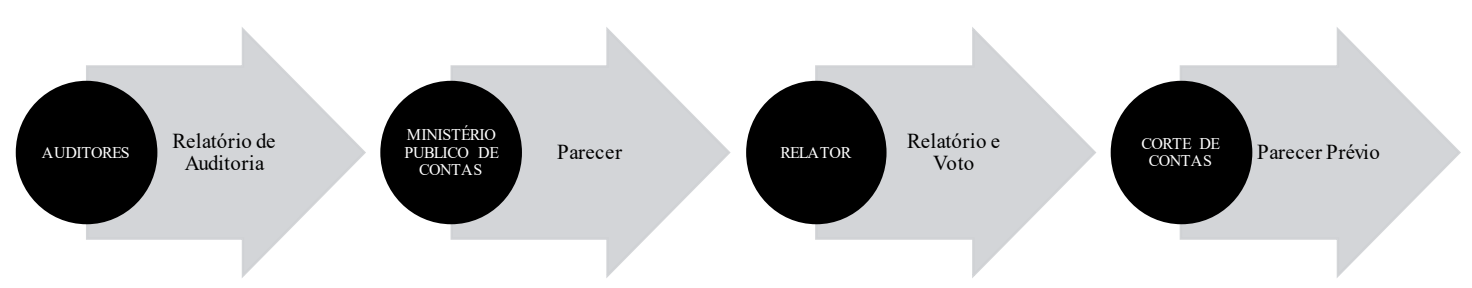

Figura 1. Ciclo da Apreciação das Contas Municipais com resultados Fonte: Elaborado pelos autores.

O relatório de auditoria, elaborado por auditores e técnicos concursados, consiste na apresentação do resultado do exame das contas anuais do município, e tem como propósito subsidiar a emissão do parecer prévio sobre as contas de governo (Resolução 14/2007 TCE/MT). Caso sejam encontradas irregularidades, tais profissionais devem tipifica-las e classifica-las de acordo com a Resolução Normativa no 02/2015 do TCE/MT. 
O relatório de auditoria é então avaliado pelo procurador concursado do Ministério Público de Contas (MPC), que elabora seu parecer (favorável ou contrário) em relação à aprovação das contas (Resolução 14/2007 TCE/MT). Após receber o parecer do MPC, um conselheiro é designado como relator. Tal designação pode ser por rodízio, sorteio ou aleatoriamente via sistema eletrônico. O relator então elabora seu relatório e o envia, juntamente com seu voto, para apreciação do plenário (todos conselheiros reunidos) da corte de contas (Resolução 14/2007 TCE/MT). A opinião da maioria dos conselheiros resulta no Parecer Prévio do Tribunal de Contas, que pode ser favorável ou contrário à aprovação das contas municipais (Resolução 14/2007 TCE/MT).

O parecer prévio sobre as contas anuais de governos manifesta a conclusão do TCE/MT sobre: (i) sua apresentação adequada, (ii) a observância dos princípios fundamentais de contabilidade e do princípio da transparência, (iii) observância dos limites constitucionais e legais na execução dos orçamentos públicos, (iv) o cumprimento dos programas previstos na LOA, a consonância com plano plurianual e a lei das diretrizes orçamentárias e (v) o resultado das políticas públicas (Resolução Normativa 10/2008 TCE/MT). Em seguida o parecer prévio é enviado para Câmara Municipal, e este só deixa de prevalecer por decisão de dois terços ou mais dos membros da Câmara (Resolução 14/2007 TCE/MT).

Em relação à composição do Tribunal de Contas de Mato Grosso, a Constituição Estadual determina que das sete vagas de conselheiros no Pleno do Tribunal, três são escolhidos pelo Governador, sendo uma de livre escolha e dois indicados pelo Tribunal em lista tríplice, alternadamente, entre auditores e membros do Ministério Público. Os outros quatro são escolhidos pela Assembleia Legislativa. Além de requisitos quanto a idade, idoneidade moral e reputação ilibada, precisam ter mais de 10 (dez) anos de exercício de função ou de efetiva atividade que exijam notório conhecimento jurídico, contábil, econômico e financeiro ou de administração pública. O ingresso dos auditores e membros do MPC como membro do pleno encontrava-se impedido por meio de exigência imposta pela Emenda Constitucional n ${ }^{\circ}$ 61/2011 bloqueou o acesso, pois exigia dez anos de função no próprio TCE/MT como requisito para concorrer a vaga de conselheiro titular. Essa exigência impossibilitava o acesso da equipe proveniente de concurso ao cargo de conselheiro efetivo, pois o quadro de conselheiros substitutos e procuradores de contas do TCE/MT somente começou a ser formado em 2009, e nesse sentido o TCE; MT viria a ter um integrante da classe técnica somente a partir de 2019 (Notícias STF 2.014).

De acordo com o Regimento Interno do TCE/MT, quando afastados, os Conselheiros titulares são substituídos pelos titulares dos cargos de Conselheiro Substituto, exercendo as mesmas atribuições com as mesmas garantias e prerrogativas. Os conselheiros substitutos ingressam por meio de concurso público de provas e títulos, cumprindo requisitos como: idoneidade moral e reputação ilibada, conhecimentos multidisciplinares, e experiência profissional. Os titulares do pleno do Tribunal do Mato Grosso são todos conselheiros oriundos de indicação política de livre escolha.

\section{METODODOLOGIA}

Foram analisados os relatórios de auditoria, os pareceres do MPC e os pareceres prévios de apreciação das contas municipais de governo, referentes aos exercícios financeiros de 2011 a 2015, de 141 (cento e quarenta e um) municípios do estado de Mato Grosso. Considerando que é assegurado ao responsável pelas contas o contraditório e a ampla defesa previstos no art. $5^{\circ}, \mathrm{LV}$, da Constituição Federal, foram consideradas apenas as irregularidades mantidas pela equipe de auditoria após a análise das justificativas, esclarecimentos, contestações e providências.

No Apêndice apresentamos a lista de irregularidades apontadas pelo Tribunal de Contas. As irregularidades (nas contas de 141 governos de 2011 a 2015) foram tipificadas de acordo com a Resolução Normativa $n^{\circ}$ 17/2010 do TCE/MT. Entre os tipos estão as irregularidades em licitação; despesa; prestação de contas; contrato; contabilidade; controle interno; gestão fiscal/financeira; pessoal; planejamento/orçamento; regime próprio de previdência social; gestão patrimonial; limites constitucionais/legais; diversos; e convênio.

Em seguida, cada irregularidade foi classificada em dois níveis de gravidade: (i) gravíssima, ou (ii) grave ou moderada. Um exemplo de irregularidade gravíssima é o não cumprimento ao limite constitucional/legal que deve ser gasto com a manutenção e desenvolvimento do ensino, caracterizado pelo percentual mínimo de $25 \%$ da receita de impostos (art. 212, da Constituição Federal). Outro exemplo é a "contração de obrigação de despesa nos dois últimos quadrimestres do mandato sem que haja disponibilidade financeira" (art. 42, caput e parágrafo único

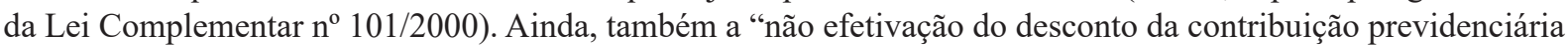
dos segurados, não-recolhimento das cotas de contribuição previdenciária descontadas dos segurados a instituição devida ou ainda o não-recolhimento das cotas de contribuição previdenciária do empregador à instituição de previdência" (Resolução normativa 17/2010 do TCE). 
Para verificar se a origem do conselheiro-relator, sendo política, diminui a probabilidade de o seu voto ser contrário à aprovação das contas municipais, foram feitos testes do seguinte modelo (Equação 1):

$$
\text { Voto do relator }_{\mathrm{i}, \mathrm{t}}=\beta_{0}+\beta_{1} \text {. Origem do relator }+ \text {. }_{\mathrm{i}, \mathrm{t}}+\text { Controles }_{\mathrm{i}, \mathrm{t}}+\varepsilon_{\mathrm{i}, \mathrm{t}}
$$

Todas variáveis na análise são binárias (1/0). Para melhor entendimento, antecipamos que as variáveis binárias que tratam de - votos e irregularidades identificadas - estão orientadas para valor 1, quando não indicam uma propensão à rejeição das contas, como a presença de irregularidades graves ou voto contrário às contas. $\mathrm{E}$ valor 0 , quando indicam uma propensão à aprovação das contas, ou seja, quando não há irregularidade graves ou os votos são favoráveis ao governo.

$\mathrm{O}$ voto do relator assume valor 1 (um) quando o conselheiro relator foi contrário à aprovação das contas, e valor 0 (zero) quando seu voto era favorável. Essa variável serpa usada como dependente no modelo para testar o que influência o voto do relator. Se o conselheiro que atua como relator naquele processo ingressou por indicação do Poder Legislativo ou do Executivo, a variável 'origem do relator' assume valor 1 (um) se ou zero (0) se ingressou por meio de concurso público.

As variáveis de controle foram divididas em três grupos: (a) contexto político do governo, (b) as irregularidades identificadas pelos auditores, e (c) posições no julgamento das contas. As variáveis de contexto político do governo seguem o estudo de Velten (2015), se o prefeito (cujas contas foram apreciadas) é reeleito atribuímos valor 1 (um) e zero nos demais casos; se o prefeito (cujas contas foram apreciadas) era do partido do governador atribuímos valor 1 (um) e zero nos demais casos, se o prefeito (cujas contas foram apreciadas) pertencia ao mesmo partido ou coligação do governador recebeu valor 1 (um) e zero nos demais casos. Se o partido do prefeito (cujas contas foram apreciadas) pertencia a algum partido de esquerda, especificamente PT, PDT, PPS, PCdoB, PSB, PV, PSTU, PCO e PMN) recebeu valor 1 (um) e zero nos demais casos.

Em relação à irregularidades identificadas pelos auditores, assume valor 1 (um) se foi apontada pelo menos uma irregularidade gravíssima no exercício e zero nos demais casos.

Por fim, as posições do MPC e conselheiros no julgamento das contas municipais, sendo que cada conta municipal recebeu valor 1 (um) quando o relatório do MPC foi contrário a aprovação das contas municipais, 1 (um) para cada voto contrário dos conselheiros à aprovação das contas municipais e zero nos demais casos.

\section{A REVERSÃO DA OPINIÃO DA AUDITORIA}

A Tabela 1 apresenta a descrição dos dados para as 706 prestações de contas de 141 municípios do estado de Mato Grosso, de 2011 a 2015. Essas prestações de contas passaram por votos do MPC, dos relatores e conselheiros, reunindo mais de 4,2 mil votos no período. 
Tabela 1. Estatística descritiva das contas municipais

\begin{tabular}{|c|c|c|c|c|c|c|c|c|}
\hline Variáveis & n & Média & D.P. & Mín & 0,25 & Mdn & 0,75 & Máx \\
\hline \multicolumn{9}{|l|}{ Contexto político do governo } \\
\hline Origem do relator & 706 & 0,83 & 0,37 & 0 & 1,00 & 1,00 & 1,00 & 1 \\
\hline Prefeito é reeleito & 706 & 0,22 & 0,41 & 0 & 0,00 & 0,00 & 0,00 & 1 \\
\hline Prefeito é do partido do governador & 706 & 0,49 & 0,50 & 0 & 0,00 & 0,00 & 1,00 & 1 \\
\hline Prefeito é de partido de esquerda & 706 & 0,24 & 0,43 & 0 & 0,00 & 0,00 & 0,00 & 1 \\
\hline \multicolumn{9}{|l|}{ Posições no julgamento das contas } \\
\hline Voto do MPC (1 - pela reprovação das contas) & 706 & 0,22 & 0,41 & 0 & 0,00 & 0,00 & 0,00 & 1 \\
\hline Voto do relator (1 - pela reprovação das contas) & 706 & 0,08 & 0,28 & 0 & 0,00 & 0,00 & 0,00 & 1 \\
\hline Parecer Prévio ( 1 - pela reprovação das contas) & 706 & 0,08 & 0,28 & 0 & 0,00 & 0,00 & 0,00 & 1 \\
\hline Voto do relator diferente do voto do MPC & 706 & 0,14 & 0,35 & 0 & 0,00 & 0,00 & 0,00 & 1 \\
\hline Parecer Prévio diferente do voto do MPC & 706 & 0,14 & 0,35 & 0 & 0,00 & 0,00 & 0,00 & 1 \\
\hline \multicolumn{9}{|l|}{ Irregularidades identificadas pelos auditores } \\
\hline Contas com irregularidades gravíssimas & 706 & 0,33 & 0,47 & 0 & 0,00 & 0,00 & 1,00 & 1 \\
\hline \multicolumn{9}{|l|}{ Irregularidades por tipo e nivel: } \\
\hline Não Classificadas & 706 & 0,11 & 0,32 & 0 & 0,00 & 0,00 & 0,00 & 1 \\
\hline Limites Constitucionais & 706 & 0,20 & 0,40 & 0 & 0,00 & 0,00 & 0,00 & 1 \\
\hline Gravíssimas em Limites Constitucionais & 706 & 0,20 & 0,40 & 0 & 0,00 & 0,00 & 0,00 & 1 \\
\hline Gestão Fiscal Financeira & 706 & 0,35 & 0,48 & 0 & 0,00 & 0,00 & 0,00 & 1 \\
\hline Gravíssimas em Gestão Fiscal Financeira & 706 & 0,20 & 0,40 & 0 & 0,00 & 0,00 & 0,00 & 1 \\
\hline Diversos & 706 & 0,10 & 0,30 & 0 & 0,00 & 0,00 & 0,00 & 1 \\
\hline Gravíssimas em Diversos & 706 & 0,00 & 0,00 & 0 & 0,00 & 0,00 & 0,00 & 0 \\
\hline Planejamento e Orçamento & 706 & 0,26 & 0,44 & 0 & 0,00 & 0,00 & 0,00 & 1 \\
\hline Gravíssimas em Planejamento e Orçamento & 706 & 0,00 & 0,00 & 0 & 0,00 & 0,00 & 0,00 & 0 \\
\hline Prestação de Contas & 706 & 0,22 & 0,42 & 0 & 0,00 & 0,00 & 0,00 & 1 \\
\hline Gravíssimas em Prestação de Contas & 706 & 0,00 & 0,00 & 0 & 0,00 & 0,00 & 0,00 & 0 \\
\hline Cotabilidade & 706 & 0,09 & 0,28 & 0 & 0,00 & 0,00 & 0,00 & 1 \\
\hline Gravíssimas na Contabilidade & 706 & 0,00 & 0,04 & 0 & 0,00 & 0,00 & 0,00 & 1 \\
\hline Despesa & 706 & 0,01 & 0,10 & 0 & 0,00 & 0,00 & 0,00 & 1 \\
\hline Gravíssimas na Despesa & 706 & 0,00 & 0,00 & 0 & 0,00 & 0,00 & 0,00 & 0 \\
\hline Controle Interno & 706 & 0,01 & 0,11 & 0 & 0,00 & 0,00 & 0,00 & 1 \\
\hline Gravíssimas em Controle Interno & 706 & 0,00 & 0,00 & 0 & 0,00 & 0,00 & 0,00 & 0 \\
\hline Pessoal & 706 & 0,01 & 0,08 & 0 & 0,00 & 0,00 & 0,00 & 1 \\
\hline Gravíssimas em Pessoal & 706 & 0,00 & 0,04 & 0 & 0,00 & 0,00 & 0,00 & 1 \\
\hline
\end{tabular}

Fonte: Elaborada pelos autores..

Nota: As irregularidades 'não classificadas' não foram classificadas quanto ao nível. As irregularidades do tipo licitação, contrato, RPPS, gestão patrimonial, gestão patrimonial e convênio, foram ocultadas da Tabela 1 por não possuirem observações.

Cerca de $83 \%$ dos relatórios de auditoria das contas de governo do periodo foram relatadas por conselheiros com indicação política; $22 \%$ das contas apreciadas pertenciam a prefeitos reeleitos; $49 \%$ das contas eram de prefeitos que pertenciam ao mesmo partido do governador; e 24\% pertenciam a partidos de orientação de esquerda.

A Resolução $n^{\circ}$ 1311/2010 (Conselho Federal de Contabilidade) versa que o auditor não pode se deixar influenciar por fatores ou quaisquer elementos materiais ou afetivos que possam resultar na perda de sua independência. Mesmo que a atuação do auditor fosse garantida como independente, a opinião qualificada pode ser revertida nas outras etapas do processo. 
Os auditores indicaram irregularidades gravíssimas em 33\% das prestações de contas após a análise da defesa. Somente os tipos Limites Constitucionais e Gestão Fiscal e Financeira são vistos como gravíssimas pelos auditores. O MPC se manifestou contrário à aprovação das contas em $22 \%$ do total das prestações, enquanto somente $8 \%$ do total das prestações de contas resultaram em Parecer Prévio Contrário. Esses resultados indicam que existe uma inversão da tendência de reprovação das contas dada presença de irregularidades gravíssimas quando a apreciação passa da equipe técnica para o pleno, o que poderiam indicar a suscetibilidade à interferência política defendida por Gomes (2006).

Como mostrado na Figura 2, o efeito das irregularidades gravíssimas para parte dos casos é revertida na fase final do processo, entre o relator e os conselheiros no plenário. A equipe técnica de auditoria encontrou irregularidades gravíssimas em 33\% das contas municipais, mas que se reverteram em apenas $8 \%$ de opinião contrária a aprovação das contas após a apreciação pelo plenário. Dos 33\% das contas com irregularidades gravíssimas, o MPC se pronunciou contrário a aprovação em $22 \%$ das contas. Ao final, dos $22 \%$, o relator seguido pelos conselheiros no pleno se pronunciaram contrário a aprovação de apenas $8 \%$ das contas municipais com irregularidades consideradas gravíssimas.
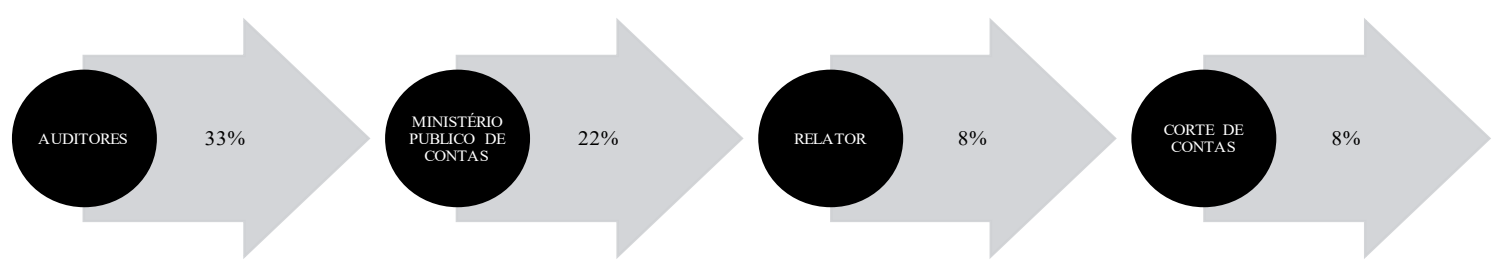

Figura 2. Reversão da importâncias das irregularidades gravíssimas ao longo do ciclo da Apreciação das Contas Municipais. Fonte: Elaborado pelos autores.

Embora o Manual de Auditoria Governamental do TCE/MT verse que via de regra, tais análises realizadas pelo corpo técnico deveriam ser o principal referencial para subsidiar os conselheiros no plenário, na maioria dos casos as irregularidades gravíssimas apontadas pela equipe técnica são ignoradas pelo pleno.

Tabela 2. Contas sem irregularidades gravíssimas

\begin{tabular}{rcccccccc}
\hline Variáveis & $\mathbf{n}$ & Média & D.P. & Mín & $\mathbf{0 , 2 5}$ & Mdn & $\mathbf{0 , 7 5}$ & Máx \\
\hline Parecer MPC diferente do Voto Individual & 2879 & 0,01 & 0,12 & 0,00 & 0,00 & 0,00 & 0,00 & 1,00 \\
Voto Relator diferente do Voto Individual & 2879 & 0,00 & 0,00 & 0,00 & 0,00 & 0,00 & 0,00 & 0,00 \\
Voto Individual & 2879 & 0,01 & 0,09 & 0,00 & 0,00 & 0,00 & 0,00 & 1,00 \\
\hline
\end{tabular}

Fonte: Elaborada pelos autores..

Nota: Esta tabela demonstra a opinião dos agentes apreciadores sobre as contas municipais que não apresentaram irregularidades gravíssimas. O parecer prévio representa o parecer sobre as contas logo após as votações que é encaminhado à Câmara de vereadores para votação.

Por fim, se consideramos as contas que não sofreram apontamentos gravíssimos, ou sofreram apontamentos somente de irregularidades moderadas ou graves (473 contas), o MPC e os relatores aprovaram as contas. Ou seja, irregularidades graves ou moderadas não são relevantes para motivarem um parecer contrário, nem mesmo para o MPC (Tabela 2).

\section{A DINÂMICA DOS VOTOS NA APRECIAÇÃO DAS CONTAS}

A análise a seguir não pretende explicar os determinantes da reprovação das contas. Mas sim como ocorre a reversão da indicação dos auditores quando passa pelo pleno, e tal inversão tem relação com a composição do pleno e da dinâmica do voto do relator e do membro do MPC. Testamos se o relator ser um indicado politicamente para função afeta o processo de apreciação. 
Como mostrado na Figura 2, a sequência de posicionamento do MPC, relator e pleno são sequenciais, primeiro o MPC se manifesta, em seguida o relator e depois o plenário de conselheiros.

A Tabela 3 apresenta um panorama dos mais de 4,2 mil votos individuais dos conselheiros do Tribunal de Contas do Estado do Mato Grosso, além dos votos dos relatores nos 706 processos. Na comparação dos votos de Relator e MPC, Relator e Conselheiros, observa-se alguns padrões.

Tabela 3. Estatística descritiva dos votos e da origem dos conselheiros

\begin{tabular}{rccccc}
\hline Variáveis & $\mathbf{n}$ & Média & D.P. & Máx & Mín \\
\hline Voto do conselheiro (pela reprovação das contas) & 4295 & 0,08 & 0,28 & 1 & 0 \\
Voto do conselheiro diferente do relator & 4295 & 0,00 & 0,03 & 1 & 0 \\
Origem do conselheiro (política) & 4295 & 0,69 & 0,46 & 1 & 0 \\
Voto do relator diferente do voto do MPC & 706 & 0,14 & 0,35 & 1 & 0 \\
Parecer Prévio diferente do voto do MPC & 706 & 0,14 & 0,35 & 1 & 0 \\
\hline Origem do relator (política) & 706 & 0,83 & 0,37 & 1 & 0 \\
\hline
\end{tabular}

Fonte: Elaborada pelos autores..

Nota: Voto do conselheiro é o voto individual do conselheiro no plenário do Tribunal, entre os quais não estão o relator e o MPC. Entre esses estão conselheiros que possuem indicação política e os que são concursados no TCE.

\section{Voto dos conselheiros seguem o relator}

Na Tabela 3, apenas $8 \%$ dos votos de todo os conselheiros que votaram nos 706 processos foram contrários à aprovação de contas, e quase $100 \%$ deles seguem o voto do relator de cada processo. O que pode sugerir que os conselheiros confiam tal decisão ao relator e cumprem um papel de legitimador do voto do relator, com baixo ceticismo profissional. Consequentemente, permance aberta a possibilidade de eventuais influências políticas surgidas na posição do relator e que segue para o parecer prévio. Não cabe a este estudo explorar as motivações particulares dos conselheiros, ou seja, nos limitamos aos números encontrados no estudo.

\section{Voto dos relatores}

O voto do relator é diferente do voto do MPC em 14\% dos casos, olhando-se para todas contas, ou seja, eles divergem em 14\% das contas analisadas. Mais de $80 \%$ dos relatórios de auditoria das contas de governo do período foram relatadas por relatores com indicação política (Tabela 3). Mas, quando o foco está nas irregularidades gravíssimas a divergência de opinões é ainda maior, ou seja, o ministério público se posicionou em contrário em 156 das 233 contas com irregularidades gravíssimas. Dessas 156 contas nas quais o Ministério Público de contas se posicionou em contrário à aprovação das contas, os relatores seguiram o Ministério Público de Contas em apenas 57 delas (divergindo do MPC em 63\% dos casos).Tal indício corrobora com Grasso e Sharkansky (2001), ao afirmar que a visão pura da independência da auditoria é insustentável quando se busca averiguar atividades que são intrinsicamente políticas.

O voto do conselheiro-relator pode direcionar os demais votos do plenário e então determinar o resultado do Parecer Prévio. A Tabela 4 apresenta o teste de média da posição dos relatores para dois grupos: relatores concursados e relatores com indicação política. A média de votos pela reprovação das contas municipais é maior no grupo de relatores concursados comparados aos de indicação política. Os últimos são mais propensos a reverter o posicionamento dos auditores, provavelmente pelas interferências políticas em seus julgamentos. 
Tabela 4. Teste de diferenças de médias dos votos dos relatores em relação ao voto do MPC

\begin{tabular}{|c|c|c|c|c|c|c|c|}
\hline \multirow[b]{2}{*}{ Voto do Relator (1-pela reprovação das contas) } & \multicolumn{2}{|c|}{ Concurso } & \multicolumn{2}{|c|}{$\begin{array}{c}\text { Indicação } \\
\text { política }\end{array}$} & \multirow[b]{2}{*}{$\begin{array}{c}\neq \\
\text { Médias }\end{array}$} & \multirow[b]{2}{*}{ P-valor } & \\
\hline & Média & D.P. & Média & D.P. & & & \\
\hline Para todos os $(n=706)$ & 0,161 & 0,369 & 0,070 & 0,255 & 0,091 & 0,001 & $* * *$ \\
\hline MPC pela reprovação das contas $(n=153)$ & 0,586 & 0,501 & 0,322 & 0,469 & 0,264 & 0,008 & $* * *$ \\
\hline MPC pela aprovação das contas $(\mathrm{n}=553)$ & 0,022 & 0,149 & 0,002 & 0,046 & 0,020 & 0,017 & $* *$ \\
\hline Casos com irregularidades gravísssimas $(\mathrm{n}=234)$ & 0,381 & 0,492 & 0,208 & 0,407 & 0,173 & 0,018 & $* *$ \\
\hline Casos sem irregularidades gravíssimas $(\mathrm{n}=472)$ & 0,040 & 0,196 & 0,003 & 0,000 & 0,037 & 0,001 & $* * *$ \\
\hline Número de Observações & 706 & & & & & & \\
\hline
\end{tabular}

Fonte: Elaborada pelos autores..

Nota: ***,**, *, Estatisticamente significantes ao nível de 1\%, 5\% e 10\%, respectivamente.

Ainda na Tabela 4, é apresentado o teste de média de voto dos dois grupos de relatores em relação ao voto do MPC e em relação às irregularidades gravíssimas. O grupo de relatores concursados votaram pela reprovação das contas em $58 \%$ das contas nas quais o MPC sugeriu também reprovar as contas, contra $32 \%$ dos indicados politicamente. Já quando o MPC se pronunciou favorável a aprovação das contas, tanto no grupo de relatores concursados quanto com indicação política, os relatores que divergiram do MPC e votaram pela reprovação das contas foram raros $(2,2 \%$ e $0,2 \%$ respectivamente).

As contas com irregularidades gravíssimas obtiveram mais votos pela reprovação das contas de relatores concursados ( $38 \%$ em média), do que no grupo de relatores indicados ( $20 \%$ em média). Se não existiam irregularidades gravíssimas apontadas, poucos votos pela reprovação foram dados nos dois grupos: (4\% no grupo de relatores concursados e $0,3 \%$ no grupo de relatores indicados). Assim, a origem do relator importa na condução do voto para o plenário, já que os conselheiros irão seguir este voto, como já demonstrado.

\section{Testes adicionais}

Os testes a seguir (Tabela 5) consideram o Contexto político do governo e as Posições nos julgamento das contas no teste Probit para estimar a probabilidade de ocorrer uma opinião contrária à aprovação das contas municipais. Resultados similares foram obtidos na estimação logit.

Tabela 5. Testes Probit para o efeito no voto do relator

\begin{tabular}{|c|c|c|c|c|c|c|}
\hline \multirow[b]{3}{*}{ Variáveis } & \multicolumn{3}{|c|}{ Painel A } & \multicolumn{3}{|c|}{ Painel B } \\
\hline & \multicolumn{3}{|c|}{ Voto Relator } & \multicolumn{3}{|c|}{ Voto Relator } \\
\hline & Coef. & P-valor & & Coef. & P-valor & \\
\hline \multicolumn{7}{|l|}{ Contexto político do governo } \\
\hline Origem do relator & $-0,721$ & 0,001 & $* * *$ & $-0,713$ & 0,003 & $* * *$ \\
\hline Prefeito é reeleito & $-0,488$ & 0,070 & $*$ & $-0,584$ & 0,034 & $* *$ \\
\hline Prefeito é do partido do governador & 0,207 & 0,281 & & 0,220 & 0,257 & \\
\hline Prefeito é de partido de esquerda & 0,175 & 0,462 & & 0,199 & 0,387 & \\
\hline \multicolumn{7}{|l|}{ Posições no julgamento das contas } \\
\hline Voto do MPC (1 - contrário à aprovação) & 2,085 & 0,000 & $* * *$ & 1,762 & 0,000 & $* * *$ \\
\hline Irregularidades gravíssimas & 0,401 & 0,260 & & & & \\
\hline Irregularidades identificadas pelos auditores & & & & & 0,506 & \\
\hline Gravíssimas em Limites Constitucionais & - & - & & 0,506 & 0,015 & $* *$ \\
\hline Gravíssimas em Gestão Fiscal Financeira & - & - & & 0,754 & 0,003 & $* * *$ \\
\hline Constante & 2,269 & 0,000 & & $-2,373$ & 0,000 & \\
\hline Número de Observações & 706 & & & 704 & & \\
\hline
\end{tabular}

Fonte: Elaborada pelos autores..

Nota: ***,**, *, Estatisticamente significantes ao nível de 1\%, 5\% e 10\%, respectivamente. As irregularidades 'não classificadas' não foram classificadas quanto ao nível. As irregularidades do tipo licitação, contrato, RPPS, gestão patrimonial, gestão patrimonial e convênio, foram ocultadas da Tabela 3 por não possuirem observações. Foram incluídas nos testes todas variáveis apresentadas na metodologia. 
A presença de irregularidades gravíssimas na Gestão Fiscal e Financeira e em Limites Constitucionais, como era de se esperar tem associação com o voto contrário à aprovação das contas emitido pelo relator. Por um lado, os relatores tendem a votar favorável à aprovação das contas municipais quando tais relatores têm indicação política (não são concursados). Contudo, tais relatores tendem a votar contrário à aprovação das contas quando o MPC inicia esse voto contrário à aprovação. Diferentemente dos achados de Velten (2015), os resultados encontrados neste estudo sugerem que a origem do relator sendo política, diminui a probabilidade de o voto do relator ser contrário a aprovação das contas (Tabela 5).

Em termos do contexto político do governo, prefeitos de partidos de esquerda e ou de partido/coligação que elegeu o governador não foram significantes na relação com o plenário do TCE. Estes resultados são similares aos de Milanezi e Monte-mor (2017). Contudo, as contas de exercícios com prefeitos reeleitos estão associadas à recomendação de aprovação das contas pelo relator. Ou seja, negativamente associadas com voto contrário a aprovação das contas emitido pelo relator. De forma geral interpreta-se dos resultados que o apontamento de irregularidades gravíssimas não influencia o voto do relator, mas que o posicionamento do MPC sim. Além disso, a origem do relator sendo política, diminui a probabilidade de o voto do relator ser contrário a aprovação das contas, contrariando os achados de Velten (2015)

\section{CONSIDERAÇÕES FINAIS}

O estudo traz evidências empíricas de que a composição do TCE/MT, preponderantemente política, e a sistemática de apreciação das contas municipais no estado de Mato Grosso, pouco tem contribuído para que o TCE/ MT possa cumprir sua missão. Tal resultado demonstra o distanciamento dos valores institucionais declarados e a baixa efetividade no aproveitamento dos recursos públicos inseridos no Tribunal anualmente, em média 350 milhões (LOA/2017).

A probabilidade de voto favorável à aprovação das contas municipais do Estado de Mato Grosso é maior quando são apreciadas pelos relatores oriundos de indicação política, mesmo na presença de irregularidades gravíssimas. O que sugere que a tendência de reprovação vinda do reatório de auditoria é revertida quando sobe para a esfera política do plenário da Corte. Ainda, as irregularidades graves e moderadas apontadas pela equipe técnica não são relevantes nem para o MPC nem para os conselheiros.

O relator indicado tem um efeito importante no processo, dado que a grande maioria dos votos dos conselheiros (inclusive dos conselheiros oriundos de concurso público) acompanha o voto do relator. Esse resultado corrobora com o que Bazerman et al. (1997), quando os autores afirmam que mesmo os auditores mais íntegros, podem vir a fornecer julgamentos influenciados por políticas institucionais.

Em termos de implicações, dada esta formação é provável que a auditora de governos esteja sendo em grande parte inócua. Seria necessária uma maior reflexão a respeito das normas para que garantissem o ingresso de técnicos ao cargo de Conselheiro Titular. Possivelmente uma solução seria a participação de órgãos de classe na indicação de técnicos, tal como acontece no judiciário. Em termos operacionais, seria benéfico um conjunto de parâmetros de conteúdo mínimo que justificasse eventual divergência entre auditores e Ministério Público nos seus posicionamentos.

Os resultados podem contribuir para a proposta de Emenda à Constituição Federal 22/2017 de iniciativa da Associação dos Membros dos Tribunais de Contas do Brasil (Atricon). Nesta proposta seria criado o Conselho Nacional dos Tribunais de Contas, e critérios e requisitos para a investidura de membros de carreria técnicas aos Tribunais, e uma maior padronização da atuação dos Tribunais de Contas.

\section{REFERÊNCIAS}

Albernaz, B., Silveira D. E., Barreira, G. (2017). Presidente e 4 conselheiros do TCE do RJ são presos em operação. Globo.G1, Rio de Janeiro, 29 mar. 2017. Recuperado em 24 abril, de http://g1.globo.com/rio-de-janeiro/ noticia/alvos-de-operacao-contra-fraude-no-tribunal-de-contas-do-rj-sao-presos.ghtml.

Araujo, P. (2017). STF determina afastamento de 5 conselheiros do TCE-MT citados por ex-governador em delação. Globo.G1, Mato Grosso, 14 set. 2017. Recuperado em 13 novembro, 2017, de https://g1.globo.com/ mato-grosso/noticia/stf-determina-afastamento-de-5-conselheiros-do-tce-mt-citados-por-ex-governador-emdelacao.ghtml.

Bazerman, M. H., Morgan, K. P., \& Loewenstein, G. F. (1997). Opinion: The impossibility of auditor independence. Sloan Management Review, 38(4), 89. 
Brasil. Tribunal Regional Federal (Goiás). Ação Direta de Inconstitucionalidade 3.602. Art. 37, II e V. Criação de Cargo em Comissão. Lei 15.224/2005 do Estado de Goiás. Inconstitucionalidade. Requerente: ProcuradorGeral da República. Requerido: Assembleia Legislativa e Governador do Estado de Goiás. Relator: Min. Joaquim Barbosa, 14 de abril de 2011.

Brasil. Senado Federal. Proposta de Emenda à Constituição PEC 22/2017. Altera o artigo 22, altera o inciso III do art. 52, altera o artigo 73, acrescenta o artigo 73-A, altera o parágrafo único do art. 75, altera a alínea "r" do inciso I do artigo 102, todos da Constituição Federal, e acrescenta os artigos 29-A e 115 ao Ato das Disposições Constitucionais Transitórias, para modificar a forma de composição dos Tribunais de Contas, criar o Conselho Nacional dos Tribunais de Contas e adotar outras providências. Disponível em: <https:// www25.senado.leg.br/web/atividade/materias/-/materia/129565. Acesso em: 05 abr. 2018.

Conselho Federal de Contabilidade. (2010). Resolução $n^{o}$ 1311/2010 - Independência -Trabalhos de Auditoria e Revisão. Recuperado em 07 novembro, 2017, de http://www1.cfc.org.br/sisweb/sre/detalhes_sre. aspx?Codigo $=2010 / 001311$.

DeAngelo, L. E. (1981). Auditor size and audit quality. Journal of accounting and economics, 3(3), 183-199. DOI: https://doi.org/10.1016/0165-4101(81)90002-1.

Dye, K. M., \& Stapenhurst, R. (1998). Pillars of integrity: the importance of supreme audit institutions in curbing corruption. Washington, DC: Economic Development Institute of the World Bank.

Gomes, E. G. M. (2006). As agências reguladoras independentes e o Tribunal de Contas da União: conflito de jurisdições. Revista de Administração Pública, 40(4), 615-630. DOI: http://dx.doi.org/10.1590/S003476122006000400006.

Grasso, P. G., \& Sharkansky, I. (2001). The Auditing of Public Policy and the Politics of Auditing: The US GAO and Israel's State Comptroller. Governance, 14(1), 1-21. DOI: https://doi.org/10.1111/0952-1895.00149.

Houghton, K., \& Jubb, C.A. (2005). Auditor independence: Regulation, oversight and inspection. In Campbell T. \& Houghton K. (Eds.), Ethics and Auditing. ANU Press. Recuperado em http://www.jstor.org/stable/j. ctt2jbj00.16

Lopes, J. E. de G., Ribeiro Filho, J. F., Pederneiras, M. M. M., \& Silva, F. D. C. da. (2008). Requisitos para aprovação de prestações de contas de municípios: aplicação de Análise Discriminante (AD) a partir de julgamentos do controle externo. Contabilidade Vista \& Revista, 19(4), 59-83.

Loureiro, M. R., Teixeira, M.A. C., \& Moraes, T. C. (2009). Democratização e reforma do Estado: o desenvolvimento institucional dos tribunais de contas no Brasil recente. Revista de Administração Pública, 43(4), 739-772. DOI: http://dx.doi.org/10.1590/S0034-76122009000400002.

Constituição do Estado de Mato Grosso. Recuperado em 06 novembro, 2017, de https://www.al.mt.gov.br/ arquivos/legislacao/constituicao_estadual.pdf.

(2011). Emenda Constitucional $n^{\circ}$ 61, de 13 de julho de 2.011. Recuperado em 06 abril, 2017, de http:// www.al.mt.gov.br/storage/webdisco/leis/ec-61-2011.pdf.

(2017). Lei $n^{\circ} 10.515$, de 26 de janeiro de 2017. Estima a Receita e fixa a Despesa do Estado de Mato Grosso para o exercício financeiro de 2017. Recuperado em 06 abril, 2017, http://app1.sefaz.mt.gov.br/0325 677500623408/7C7B6A9347C50F55032569140065EBBF/F71C1338448654DC842580B500582FD2.

Milanezi, A. R. \& Monte-Mor, D. S. (2017). O efeito da utilização de créditos adicionais suplementares no julgamento das contas anuais dos municipios capixabas. Anais do Congresso ANPCONT, 11., Belo Horizonte, MG, Brazil.

Ott, E., Kruger, G. P., \& Kronbauer, C. A. (2011). Análise dos Fatores Explicativos das Inconformidades Apontadas pelo TCE/RS nas Auditorias em Executivos Municipais da Região Metropolitana de Porto Alegre. Anais do Encontro da ANPAD, 35., Rio de Janeiro, RJ, Brasil.

O Dia, Rio de Janeiro. QUATRO dos nove ministros do TCU são citados em investigações. Recuperado em 26 abril, 2017, de http://odia.ig.com.br/brasil/2017-04-02/quatro-dos-nove-ministros-do-tcu-sao-citados-eminvestigacoes.html.

Supremo Tribunal Federal. Notícias STF. Recuperado em 24 abril, 2017, de http://www.stf.jus.br/portal/cms/ verNoticiaDetalhe.asp?idConteudo=282526. 
Suzart, J. A.S. (2012). Ser ou não ser independente? Um estudo exploratório sobre a independência das Instituições Superiores de Auditoria e o nível de transparência fiscal dos países. Revista Universo Contábil, 8(3), 24-39.

Tepalagul, N., \& Lin, L. (2015). Auditor independence and audit quality: A literature review. Journal of Accounting, Auditing \& Finance, 30(1), 101-121. DOI: https://doi.org/10.1177/0148558X14544505.

Tribunal de Contas do Estado de Mato Grosso. (2017). Identidade da Instituição. Cuiabá. Recuperado em 21 agosto, 2017, de http://www.tce.mt.gov.br/conteudo/sid/767.

. (2013). Manual de Auditoria Governamental do Tribunal de Contas de Mato Grosso. Cuiabá. Recuperado em 12 junho, 2016, de http:// www.tce.mt.gov.br/conteudo/download/id/42827.

. (2014). Parecer 041/2012. Consulta Técnica. Cuiabá. Recuperado em 04 abril, 2017, www.tce.mt.gov. br/protocolo/documento/num/111872/ano/2012/numero_documento/21292/ano_documento/2012/hash/cb35 e272f9214c626669425e4db1f78a +\&cd=1\&hl=pt-BR\&ct $=$ clnk\&gl=br.

. (2007). Regimento Interno do TCEMT, Resolução № 14, de 02 de outubro de 2007. Cuiabá. Recuperado em 12 junho, 2016, de http://www.tce.mt.gov.br/legislacao?categoria=10.

. (2014). Resolução 02 de 24 de fevereiro de 2015. Altera a Resolução Normativa $n^{\circ}$ 17/2010. Cuiabá. Recuperado em 12 junho, 2016, de http://www.tce.mt.gov.br/legislacao?categoria=12.

. (2014). Resolução 10 de 25 de novembro de 2008. Estabelece Regras para Apreciação das Contas. Cuiabá. Recuperado em 12 junho, 2016, de http://www.tce.mt.gov.br/legislacao?categoria=12.

(2010). Resolução 17 de 25 de novembro de 2010. Atualiza a classificação das irregularidades para apreciação e julgamento das contas anuais de governo e de gestão a partir da competência. Recuperado em 07 dezembro, 2010, de https://www.tce.mt.gov.br/arquivos/downloads/00021191/ Resolu\%C3\%A7\%C3\%A30\%20Normativa\%20n\%C2\%BA\%20017-2010.pdf.

Velten, S. R. (2015). Determinantes da rejeição das prestações de contas anuais dos municípios capixabas pelo Tribunal de Contas do Estado do Espírito Santo. 98 p. Dissertação (Mestrado em Ciências Contábeis) da Fundação Instituto Capixaba de Pesquisas em Contabilidade, Economia e Finanças (FUCAPE), Vitória.

Yu-Cheng, L.; Yu-Hsin, L.; Fang-Chi, L.; Yi-Chen, L. (2017). Net Losses and the Relationship between Auditor Independence and Client Importance: Evidence from a Cubist Regression-Tree Model. Journal of Emerging Technologies in Accounting, 14(1), 13-25. DOI: https://doi.org/10.2308/jeta-51673.

\section{Como citar este artigo}

Azambuja, P. A., Teixeira, A., \& Nossa, S. N. (2018). Aprovação de contas municipais com irregularidades gravíssimas: quando a auditoria técnica não é suficiente. Revista de Contabilidade e Organizações, 12:e149212. DOI: http://dx.doi.org/10.11606/issn.1982-6486.rco.2018.149212 


\section{APÊNDICE - Lista de Irregularidades}

\begin{tabular}{|c|c|}
\hline Tipo de irregularidades & \\
\hline Não classificadas & \multirow{15}{*}{$\begin{array}{l}\text { Variável binária: } 1 \text { (um) nas prestações contas com } \\
\text { apontamento da irregularidade pela equipe técnica de } \\
\text { auditoria e } 0 \text { (zero) nos demais casos. }\end{array}$} \\
\hline Licitação & \\
\hline Despesa & \\
\hline Prestação de Contas & \\
\hline Contrato & \\
\hline Contabilidade & \\
\hline Controle Interno & \\
\hline Gestão fiscal/financeira & \\
\hline Pessoal & \\
\hline Planejamento/Orçamento & \\
\hline Regime Próprio de Previdência Social (RPPS) & \\
\hline Gestão Patrimonial & \\
\hline Limites Constitucionais & \\
\hline Diversos & \\
\hline Convênio & \\
\hline Nivel de criticidade da irregularidade & \multirow{15}{*}{$\begin{array}{l}\text { Variável binária : } 1 \text { (um) nas prestações contas em que a } \\
\text { equipe técnica de auditoria classificava a irregularidade } \\
\text { apontada como gravíssima e } 0 \text { (zero) nos demais casos. }\end{array}$} \\
\hline Licitação & \\
\hline Despesa & \\
\hline Prestação de Contas & \\
\hline Contrato & \\
\hline Contabilidade & \\
\hline Controle Interno & \\
\hline Gestão fiscal/financeira & \\
\hline Pessoal & \\
\hline Planejamento/ Orçamento & \\
\hline Regime Próprio de Previdência Social (RPPS) & \\
\hline Gestão Patrimonial & \\
\hline Limites Constitucionais & \\
\hline Diversos & \\
\hline Convênio & \\
\hline
\end{tabular}

